The Montessori teaching method, used most often in elementary and secondary education, is also based upon an action-oriented (not to mention sensorially based) curriculum, and it is an approach that is gaining popularity in public schools. If it is true that many contemporary college students have not achieved the highest level cognitive skills, it may be incumbent upon faculty to adjust their teaching to reflect that reality.

\section{Note}

1. The research reported here was made possible by NSF Instrumentation and Laboratory Improvement Program Grant \# USE9251254 and by matching funds from Grambling State University.

\section{References}

Friere, Paulo. 1970. Pedagogy of the Oppressed. New York: Continuum.

Hamilton, Lawrence C. 1990a. Modern Data Analysis: A First Course in Applied Statistics. Pacific Grove, CA: Brooks/Cole. . 1990b. Statistics with STATA. Pacific Grove, CA: Brooks/Cole.

Hoefler, James M. 1994. "Critical Thinking and the Use of Optical Illusions." $P S$, 27:538-45.

Hudak, Mary, and David E. Anderson. 1990. "Formal Operations and Learning Styles Predict Success in Statistics and Computer Science Courses." Teaching of Psychology 17:231-34.

Montessori, Maria. 1967. The Absorbent Mind. New York: Dell.

Rogers, P. M., and C. Manrique. 1992. "The Dilemma of Teaching Political Science Research Methods: How Much Computers? How Much Statistics? How Much Methods?" PS 25:234-37.
Whimbey, Arthur, and Jack Lochhead. 1986. Problem Solving and Comprehension. 4th ed. Hillsdale, NJ: Laurence Earlbaum.

\begin{abstract}
About the Author
Allan McBride is an associate professor of political science at the University of Southern Mississippi where he teaches statistics and research methods. His research interests are in the area of political communication,

political culture, and political behavior. His articles have appeared in Political Communication Review, Journal of Popular Culture (forthcoming), American Journal of Political Science, and $P S$.
\end{abstract}

\title{
Where Does Policy Analysis Belong in the Undergraduate Public Administration Major?
}

\author{
Robert H. Carver, Stonehill College
}

The practice of public policy analysis draws upon multiple disciplines and perspectives: analyses may rest on the methods and tools of economics, political science, operations research, history, sociology, and/or psychology, dealing with substantive issues across a wide realm. This type of multidisciplinary analysis and reporting requires a certain level of skill and experience. Perhaps this is why courses in policy analysis tend to appear in the curricula of graduate public administration programs more often than they do in undergraduate curricula.

In another vein, throughout the undergraduate curriculum, departments have been introducing senior capstone courses in recent years. For undergraduate programs in public administration, the idea of a senior-year capstone course is appropriate, but schools need not create new courses solely for this purpose. Undergraduate PA programs would do well to require a rigorous course in public policy analysis.

Such a course has an appropriate place in the core of a PA program and is also well suited to serve as an integrating experience for students nearing completion of the PA program.

Swain (1993) has made the case that policy analysis should be the vehicle for integrating public policy into the graduate public administration curriculum. I submit that policy analysis can integrate the component parts of the undergraduate major and be considered as a candidate for a capstone course.

\section{Policy Analysis and Public Administration}

The origins of policy analysis and of public policy as a field of study may evoke some unpleasant memories for public administration scholars.
Indeed, a conspicuous element of the public policy movement was its explicit rejection of public administration. The founders of the new programs gave intellectual reasons for this decision: public administration was descriptive rather than prescriptive, it was preoccupied by institutions rather than choice and action, it wore the blinders of a single discipline (political science) and was lacking in interdisciplinary vision. But the reasons were in fact political as well as intellectual (Stokes 1986).

Ironically, as public policy curricula have evolved, they increasingly have included institutional analysis. Similarly, policy evaluation and policy analysis have become increasingly important in the practice of public administration. In part, this may reflect the prominance of the administrative rationality paradigm of organization. The attempts to rationalize policy making using techniques drawn from various disciplines, and to study 
the process of policy making follow logically from that model (Heineman, et al. 1990; Ott, Hyde, and Shafritz 1991).

Although the rational model is not universally embraced, it surely describes what many public managers do, attempt to do, or believe they ought to attempt to do.

Analysis is a major activity in American government at all levels. The literature on the uses and effects of policy analysis in federal agencies, the Congress, state houses, city halls, and elsewhere is abundant (see, for example, Weiss 1989; Wildavsky 1979; Heineman, et al. 1990; Carlucci 1989; and Mitchell 1991). Policy and evaluation shops have proliferated and routinely do the kind of work that a decade ago might have required consultants. With the advent of personal computing, the Internet, and analytic training across undergraduate curricula, there is also a huge potential for personnel at lower levels to perform analysis that has been the domain of specialists. Moreover, as the states have become increasingly responsible for various policy areas, the need for state-level policy analysis can be expected to grow (Hebert, Wright, and Brudney 1992). With the growing emphases on service delivery, on productivity, on competition between public and private providers, and on quality management, the need for analysis in public organizations will surely increase.

Policy analysis occurs at diverse organizational levels. Carlucci (1989) describes the growing role of professional staff in state legislatures. At both the state and municipal levels, the near-total permeation of computing has made analysis possible in offices that might not have had appropriate capacity a few years ago (see Kraemer and Northrup 1989; Hebert, Wright, and Brudney 1992). Mitchell's study of Public Authority chief executives (1991), identified nine critical skill areas for public authority management. Six of the nine involved analytical skills.

\section{Public Administration and Policy Analysis at the Undergraduate Level}

Policy analysis is part of the intellectual foundation of public administration (Elmore 1986). Indeed, the standards accepted by the National Association of Schools of Public Affairs and Administration (NASPAA) in 1988 reflect this position, and include analysis among the required areas for M.P.A. programs.

\section{Though the M.P.A. is a professional degree, the goals of the B.A. in public administration are less clear.}

Though the M.P.A. is a professional degree, the goals of the B.A. in public administration are less clear. The question of whether undergraduates ought to study public administration is beyond the scope of this article. The focus here is on schools that do offer the major program. Although institutions offer the degree and students pursue it for a variety of reasons, any undergraduate major ought to

have a central core of method and theory that serves as an introduction to the explanatory power of the discipline, provides a basis for subsequent work, and unites all students who join in the study in a shared understanding of its character and aims. It will force students to experience the range of topics that the discipline addresses and the variety of analytic tools that it uses. It will have a sequence that presumes advancing sophistication. . . . It should give students experience with the tools of the disciplines, acquaint them with their history and philosophical presuppositions, and provide them with a strong sense of their limits and power as instruments for understanding human society (Association of American Colleges, 1985, p. 29, emphasis added).

As introduction to the discipline, the major should, at a minimum, expose the student to those concepts that form the core of public administration. Beyond that, the student should develop an increasingly sophisticated understanding of those ideas through in-depth study. Given the nature of analysis, a course in public policy analysis requires students to refine their understanding of core ideas-such as agenda setting, rational choice, present and future value, externalities, organizational behavior and bureaucratic politics-in an active way (Starling 1988). Core ideas may be treated in other courses, but it is hard to imagine doing analysis without confronting all of these ideas. The course in policy analysis is an ideal opportunity for their treatment in a problem-solving context, and for their integration.

One frustration in teaching undergraduates is that students often compartmentalize their academic experience (perhaps we teach them to do so!). Substantive material remains lodged in the temporal, physical, or departmental locus of its origin. The thrust of the recent movement to capstone courses is that students need instruction in and opportunities for integrating what they have learned.

A capstone course is one that by design calls upon students to revisit, integrate, and use much of the knowledge and insight developed in prior coursework. The literature on teaching in various disciplines is replete with suggestions for capstones both in undergraduate and graduate programs (see Wallace 1988; Jauch, Snodgrass, and Szewczak 1989; Decker and Lont 1990; and Siegfried et al. 1991). Often, the recommendation is to develop new courses specifically as capstones (e.g., Magner 1990). For public administration, a course in policy analysis can go a long way to providing a capstone experience without the need to invent a course de novo.

With policy analysis as a capstone course, seniors will have seen an example of interdisciplinary work focusing on complex problems. More to the point, they will gain experience with the application of various analytic tools and theories at a time when they have 
matured sufficiently to confront the complexities and subtleties involved. As Siegfried et al. (1991) note in reference to the economics major, "[i]t is only through continued and extensive practice that the process of thinking like an economist becomes internalized and an integral component of one's intellectual equipment" (p. 201, emphasis added).

Besides the explicit demand that students use diverse tools, skills, and theory from their prior coursework in a course in policy analysis, there are two other benefits for the student. First, as a course in applied theory and techniques, policy analysis bridges the gap between theory and practice, between the academic and "real" worlds. The course involves active, rather than passive learning, possibly stimulating the post-baccalaureate environment in which students will find themselves (Heineman, et al. 1990; O'Hare 1991).

Second, if students do independent, team-based projects in such a course, they can appreciate the power and the limits of the techniques involved, as well as the power of their own independence. They can experience the accomplishments of untangling complex interests and policy consequences, of dealing with messy and incomplete data, of explaining their analysis and findings, and of discovering some structure in their field (Williams, Stephenson, and Webber 1991; Barzelay and Kaboolian 1990). To be sure, this can be and is done in other courses, but it must be done in a rigorous course in policy analysis. The potential for these diverse and important experiences especially recommends policy analysis for a capstone role in the curriculum.

Whether directly involved in the analysis, or in the critical reading of conflicting analyses, a public administrator ought to be able to understand the language, the methodology, and biases of analyses.

Emmert, Crow, and Shangraw predict that future public managers and public organizations will need to "be able to respond to increasingly sophisticated clients who have a sound understanding of complex public policy issues. These clients, rather than being homogeneous masses, will be organized around clusters of shared interests" $(1993,352)$.

\section{Review of Current Curricula}

Where does policy analysis fit in current curricula? Although my concern here is with undergraduate curricula, I begin with a brief look at graduate programs for two reasons. First, graduate curricula articulate the state of the art, and undergraduate programs should reflect current thinking, especially since one goal of an undergraduate major is preparation for graduate training. Second, one cannot say whether "few" or "many" undergraduate programs require courses in policy analysis without knowing the score at the graduate level.

\section{Graduate Programs}

The number of M.P.A. programs requiring a course in public policy analysis has grown, but is low considering the 1988 standards set forth by the National Association of Schools of Public Affairs and Administration (NASPAA). John Ellwood's 1979 survey of 183 NASPAA institutions found that $35.7 \%$ of the programs required at least one course in policy analysis or evaluation (cited in Friedman 1991). Later, Ellwood found that policy analysis was a specialization in $31.8 \%$ of 107 NASPAA schools completing self-studies between 1979 and 1983 (cited in Cleary 1990).

Cleary (1990), sampling 31 graduate public administration programs, found a policy course of some description (including policy making, but not necessarily policy analysis) in the core in $80.6 \%$ of the programs. In his full survey of 173 M.P.A./M.P.P. programs, he found $43.8 \%$ with a specialization in policy analysis. The likelihood of a core policy course varied according to the organizational setting of the program. Political science and public affairs programs were least likely to require a policy course, and business and public policy programs were most likely to do so.

Roeder and Whitaker (1993) took exception to Cleary's categorization of courses and topics, noting that there is not necessarily a oneto-one mapping between courses and curriculum components. They did not specifically estimate the frequency of required policy analysis courses, but found that M.P.A. core requirements averaged approximately the equivalent of two full courses in analytic techniques, with individual schools varying from about one-half of one course to nearly four courses in such techniques. Not surprisingly, they also found that M.P.A. programs with an analytical focus were more likely to emphasize financial administration, techniques of analysis, and economic institutions than were M.P.A. programs with an institutional-management focus.

Both the Cleary and the Roeder and Whitaker studies also investigated the organizational location of the programs. M.P.A. programs were found principally within Colleges of Arts and Sciences, in departments of political science, government, or public administration; in separate schools of public administration or public affairs; in schools or departments of business administration. With respect to policy analysis, Roeder and Whitaker reported that "programs in business schools or public affairs administration units are somewhat more likely to emphasize techniques of analysis than programs in political science departments $\left(\chi^{2}=11.7, \mathrm{p}<.07\right)$ " (528).

Averch and Dluhy (1992) sampled 35 NASPAA institutions and 16 member schools of the Association for Public Policy Analysis and Management (APPAM), finding a core course in policy analysis in $46 \%$ of the NASPAA schools and $44 \%$ of the APPAM schools. Half of the NASPAA programs required a course in the policy process, and nearly all had at least one course in research methods or statistics. In regard to the proportion in the APPAM sample, the authors noted that a requirement might be redundant, since required projects and seminars may provide the equiva- 
lent of a separate course in analysis. The authors did not consider institutional location of the graduate program as a variable.

Policy analysis is increasingly part of the M.P.A. core, and about $45 \%$ of M.P.A. programs now require such a course. Given the trend of the past decade and the NASPAA standards, it is likely that the typical M.P.A. program will soon require policy analysis, regardless of the focus or orientation of the program, and possibly independent of institutional location.

\section{Undergraduate Programs}

There is very little literature on the place of policy analysis per se in the core of undergraduate programs. I therefore sampled 45 colleges and universities nationwide that offer an undergraduate major in public administration, reviewing the public administration requirements for each. Peterson's Guide to Four-Year Colleges (1993) lists 249 U.S. schools with such majors. For my purposes, a "policy analysis" course is one that involves the application of political, economic, and quantitative techniques. I excluded courses solely in statistics or research methods.

In the sample, $33 \%$ of the schools require a core course in policy analysis, and another $11 \%$ offer the course as an elective. I found no significant differences in this regard between public and private schools, or among schools with small, medium, or large undergraduate enrollments. Thus, undergraduate programs are less likely than M.P.A. programs to require the study of policy analysis, though the M.P.A. figure of about $45 \%$ is barely within the margin of error for the sample.

One can speculate about the reasons for the relative rarity of policy analysis in the undergraduate curricula. Part of the story may well rest with differences in the organizational location of the program in various schools, and with the availability of interested faculty. This is a matter for further investigation, and it seems plausible that the predelictions for analysis will follow similar patterns as in graduate programs.

\section{At what cost?}

The benefits of teaching policy analysis to undergraduates and of placing it in a capstone position come at a cost, and the costs fall into three categories. First, a school may have no one on the faculty available or equipped to teach the course, and thus direct budgetary costs may be attached to a required capstone course in policy analysis. Second, coordination and

... it is likely that the

typical M.P.A. program will soon require policy analysis, regardless of the focus or orientation of the program, and possibly independent of institutional location.

opportunity costs are associated with an additional requirement: students lose some flexibility in their programs, and may have to forego studying something else, while faculty members have another core course to cover. Third, particularly in programs that are already quite quantitative or specialized, the undergraduate major could become too vocational or narrow, and that may have undesirable consequences for the discipline. These costs will vary across institutions, and naturally must be considered on a case-by-case basis.

\section{Further Research}

There are at least three areas for further study here. First is the question of goals for undergraduate study in public administration. While a rich literature exists on graduate education in the field, comparatively little can be found concerning the undergraduate mission.
The second area is the current state of undergraduate curricula. My small sample should be pursued in a larger, more detailed analysis. In particular, we would benefit from understanding why the observed differences in core requirements exist. As noted above, for example, does the institutional location or orientation account for some of the differences?

The third is an up-to-date study of the career paths of graduates and of the skills needed in their positions. Evidence in the literature shows that the abilities to do analysis and to communicate its meaning are in demand at low-level jobs, but further investigation is clearly necessary on this point.

\section{Conclusion}

A required course in public policy analysis can serve as a natural capstone experience for undergraduate curricula in public administration. Such an arrangement would not serve the needs and traditions of all schools, nor would it necessarily serve the needs of the discipline were all schools to follow suit. In those cases where colleges or universities are contemplating the introduction of a capstone course, or are using another capstone course without satisfactory results, policy analysis ought to be a viable option.

Policy analysis need not be the exclusive property of graduate education. A distinct role is possible for it in undergraduate institutions, and not merely as a "sneak preview" of graduate school. By teaching analysis, rather than teaching about analysis, undergraduate programs can integrate other elements of the curriculum, prepare students for further graduate education, and equip students to understand the policy process more fully.

\section{References}

Association of American Colleges. 1985. Integrity in the College Curriculum: A Report to the Academic Community. Washington, DC: Association of American Colleges. 
Averch, Harvey, and Milan Dluhy. 1992. "Teaching Public Administration, Public Management and Policy Analysis: Convergence or Divergence in the Masters Core." Journal of Policy Analysis and Management 11(3):541-51.

Barzelay, Michael, and Linda Kaboolian. 1990. "Structural Metaphors and Public Management Education." Journal of Policy Analysis and Management, 9(4):599610.

Carlucci, Carl P. 1989. "The Role of Legislative Staff." Journal of Management Science and Policy Analysis 7(1):21-33.

Cleary, Robert E. 1990. "What Do Public Administration Masters Programs Look Like? Do They Do What Is Needed?" Public Administration Review 50(6):663 73.

Decker, Warren, and Cindy Lont. 1990.

"The Capstone Course in Speech Communication: Format and Purpose." $A C A$ Bulletin 72:51-59.

Elmore, Richard F. 1986. "Graduate Education in Public Management: Working the Seams of Government." Journal of Policy Analysis and Management 6(1):6983.

Emmert, Mark A., Michael Crow, and R. F. Shangraw, Jr. 1993. "Public Management in the Future: Post-Orthodoxy and Organization Design." In Barry Bozeman, ed. Public Management: The State of the Art. San Francisco: Jossey-Bass.

Friedman, Lee S. 1991. "Economists and Public Policy Programs." Journal of Policy Analysis and Management 10(2):34359.

Hebert, F. Ted, Deil S. Wright, and Jeffrey I. Brudney. 1992. "Challenges to State Governments: Policy and Administrative Leadership in the 1990's." Public Productivity and Management Review, XVI, no. 1 (Fall), pp. 1-21.
Heineman, Robert A., William T. Bluhm, Steven A. Peterson, and Edward N. Kearny. 1990. The World of the Policy Analyst: Rationality, Values, and Politics. Chatham NJ: Chatham House.

Jauch, Lawrence R., Coral R. Snodgrass, and Edward J. Szewczak. 1989. "Capstone Renaissance $=$ Simulation + Interaction + DSS." Simulation and Games 20(1):3-13.

Kraemer, Kenneth L., and Alana Northrup. 1989. "Curriculum Recommendations for Public Management Education in Computing: An Update." Public Administration Review 49(5):447-53.

Magner, Denise K. 1990. "Many Colleges Design Courses and Programs to Prepare Seniors to Live in the 'Real World'." Chronicle of Higher Education 36(27): A33, A35.

Mitchell, Jerry. 1991. "Education and Skills for Public Authority Management." Pub lic Administration Review. 51(5):429-37.

National Association of Schools of Public Affairs and Administration. 1988. "Standards for Professional Masters Degree Programs in Public Affairs and Administration." Washington: NASPAA.

O'Hare, Michael. 1991. "Formal Models and Government: Teaching to Do." Journal of Policy Analysis and Management 10(3):519-41.

Ott, J. Steven, Albert C. Hyde, and Jay M. Shafritz, eds. 1991. Public Management: The Essential Readings. Chicago: Nelson Hall.

Peterson's Guide to Four-Year Colleges. 1993. 23rd ed. Princeton NJ: Peterson's Guides.

Roeder, Phillip W., and Gordon Whitaker. 1993. "Education for the Public Service: Policy Analysis and Administration in the M.P.A. Core Curriculum." Administration and Society 24(4):512-40.
Siegfried, John J., Robin L. Bartlett, W. Lee Hansen, Allen C. Kelley, Donald N. McCloskey, and Thomas H. Tietenberg. 1991. "The Status and Prospects of the Economics Major." Journal of Economic Education 22(3):197-224.

Starling, Grover. 1988. Strategies for Policy Making. Chicago: Dorsey.

Stokes, Donald E. 1986. "Political and Organizational Analysis in the Policy Curriculum." Journal of Policy Analysis and Management 6(1):45-55.

Swain, John W. 1993. "Public Administration and Policy Analysis: Beyond Political Science." International Journal of Public Administration 16(8):1153-1175.

Wallace, Richard Cheever. 1988. "A Capstone Course in Applied Sociology." Teaching Sociology 16(1):34-40.

Weiss, Carol. 1989. "Congressional Committees as Users of Analysis." Journal of Policy Analysis and Management (8)3: 411-31.

Wildavsky, Aaron. 1979. Speaking Truth to Power: The Art and Craft of Policy Anal ysis. Boston: Little, Brown.

Williams, David G., Max O. Stephenson, Jr., and David J. Webber. 1991. "Teaching the Missing Pieces of Policy Analysis." PS: Political Science Politics (24)2: 218-20.

\section{About the Author \\ Robert Carver teaches business and public administration at Stonehill College in North Easton, Massachusetts, where he is also affiliated with the Joseph Martin Institute for Law and Society. His current research interests include environmental adaptation in public organizations and the business- government interface.}

\title{
Mission Impossible? Making a Political Science Final Exam That's Fun to Grade
}

\author{
John L. Seitz, Wofford College
}

About ten years ago, before he died, a colleague of mine from the philosophy department made a curious statement about final exams. (Walt made many curious statements, but this one I especially remember.) He said that he enjoyed correcting his students' final examinations because he found them fun to read. He would make up questions that didn't call for the recital of factual material, but rather called upon his students to display original thinking on some philo- sophical topic. Walt said he was never sure what the students would come up with in their answers. I remember thinking at the time that such an exercise would be very hard to do in my field and impossible to grade.

It is ten years later, and I have just finished grading about 40 final examinations from my two "Introduction to Political Science" classes. As I was grading the overview question, the one that is supposed to integrate the whole semes- ter's work, I realized that I had made a question that was somewhat like Walt's.

The dean's instructions are that final examinations should cover the semester's work. I always found that hard to do in my introductory courses where large amounts of information are presented on a wide range of topics. I struggled with that instruction until, a few years ago, I came up with an idea for a question that should satisfy the dean. It is a reasonable ques- 